\title{
An interlocking side mill with retrofittable carbide blades for processing of coarse-pitch tooth wheels
}

\author{
Evgeniy V. Artamonov ${ }^{1}$, Vitaliy V. Kireev ${ }^{1}$, and Vitaliy A. Zyryanov ${ }^{1, *}$ \\ ${ }^{1}$ Tyumen industrial university, Tyumen, Russian Federation
}

\begin{abstract}
Nowadays Russian manufacturers of metal-cutting tools for machine-building industry do not offer structures of prefabricated cutting hobs with retrofittable carbide blades for processing of tooth wheels, though usage of retrofittable carbide blades allows to increase significantly working capacity and productivity of the processing. As of today creation of an assembly cutting tool for processing of tooth wheels with the retrofittable carbide blades is a big step forward for machine-building industry. A high quality tool allows warranting for a new equipment and making work of operators more productive. This paper offers a new technical solution providing increase of efficiency of processing by assembly tools with the retrofittable carbide blades made of a hard alloy. Due to usage of progressive cutting patterns division of a margin for straight-line segments and curved sections is performed. This division has a positive impact on cutting hard-alloy inserts and also reduces their wear and tear.
\end{abstract}

In accordance with state program of RF "Development of industry and increase of its competitiveness" the task of perfection of structures of the assembly tools for processing of the coarse pitch tooth wheels equipped with cutters made of tool hard alloys with the purpose of a significant increase of productivity and working capacity is essential. Many leading countries such as Germany, Switzerland, USA, Japan develop actively manufacturing of a metal-cutting tool and contribute a lot in their economics.

The high quality instrument allows fast warranting for a new equipment, significant increase of productivity of the old equipment and make work of the operators more productive. Production of a solid tool for processing of the coarse pitch tooth wheels is not cost-effectively. Regrinding of such tool is also very complex and laborious. With the development of the industry manufacturers started active transfer from the tool made of rapid steel to a hard alloy one (Fig. 1).

\footnotetext{
*Corresponding author: macho 9208@mail.ru
} 


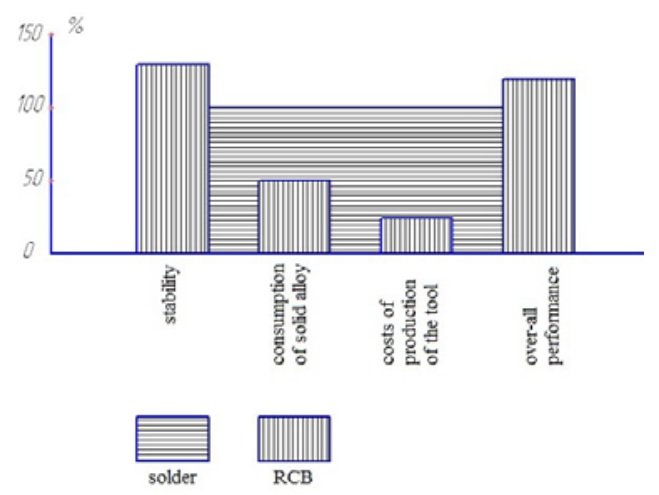

Fig. 1. Advantages of the assembly tool with RCB (retrofittable carbide blades).

Nowadays creation of the assembly cutting tool for processing of the tooth wheels with the retrofittable carbide blades is a big step forward for the machine-building industry. As opposed to the cutting hobs with a relieved tooth, the tool with RCB allows: multiple usage of a case, exclusion of necessity of braze and rounding of blades, shortening of time required for a change of the tool, increase processing modes, lack of correction in adjustment of equipment during change of RCB [1-2].

Gear milling of the tooth wheels is a laborious and complex process which imposes significant requirements to the tool because of variable loads [3-5].

Despite that manufacturing of tooth wheels has been lasting for many years already, still works on development of processing ways and creation of new metal-cutting tools are conducted because mankind haven't created an "ideal" tool yet.

The results of the research shown on picture 2 [7] are necessary to help in search of solutions in a sphere of a new tool creation [6], in search of optimal way to bind cutter plates, the tool modification and reducing of loads during processing.

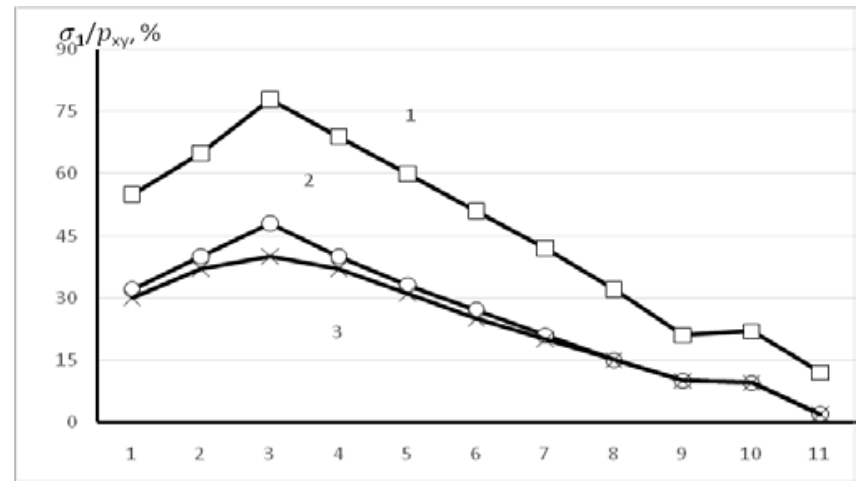

Fig. 2. Dependence of principal stresses form geometrical sizes of the plate. 1) $1=11 \mathrm{~mm} ; \mathrm{S}=3,18$ $\mathrm{mm}$;2) $\mathrm{l}=16,5 \mathrm{~mm} ; \mathrm{S}=4,76 \mathrm{~mm}$;) $\mathrm{l}=22 \mathrm{~mm} ; \mathrm{S}=4,76$

The diagram visualizes that impact of the plate thickness is more significate than its length. But it doesn't do to forget about an economic component and cost of the tool hard alloy used for manufacturing of retrofittable carbide blades. Consequently increase of the plate is not always feasible. That is why we are of opinion that it is effectually to use tangential placement of the blade inserts in the case of the tool during manufacturing of an interlocking side mill. This method allows saving of the tool hard alloy usage, providing of stability of RCB positioning in the case of the tool, improvement chip flow from the cutting 
zone, providing of easy access to fixing screws during a replacement of the blade inserts. Figure 3 shows realization of a progressive cutting pattern by a division of a machining stock during gear milling by means of tangential placement of RCB in the case of the tool.

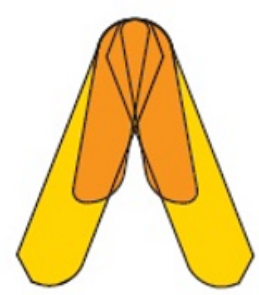

Fig. 3. Division of machining stock by means of tangential placement of the blade inserts in the case of the tool.

As a result of designing we received 4 types of different rack-type tools on the cutting tool (Fig. 4).

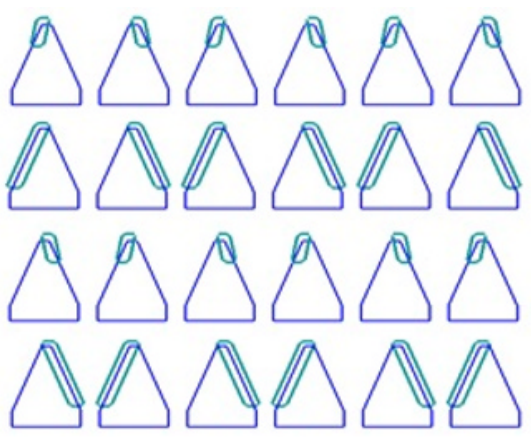

Fig. 4. Profiles of rack-type tools during tangential placement of RCB.

Usage of this pattern will allow to reduce wear and tear of the cutting tool [8-11] by means of segmentation of chip cut by razor edges. Due to this, the chip changes into a simple one, that allows to reduce surface stresses which influence on a cutting edge of the tool. Due to changes of such kind of the cutting pattern wear and tear and destruction level of the tool edges reduces.

A construction of an assembly cutting hob for processing of the tooth wheels with mode $\mathrm{m}=14$ (fig. 5) was designed with the help of software "Compass - 3D".

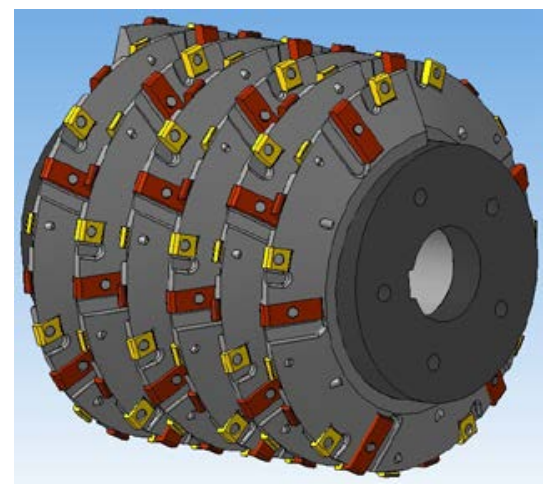

Fig. 5. The construction of the assembly cutting hob 
The cutting hob consists of separate discs 1 . Case of these discs forms a skewed surface 13 which has a definite ascending angle $\omega$. The skewed angle has tangential slots 2 with surfaces bearing required for placement of the cutting elements in them, hole 3 for a placement of a key-slotted plug and five through-holes 4 for locking pins. Side 5 and principal 6 cutting blades based in angle slots are fastened on each disc with the help of screws 7 (fig. 6, a, b).

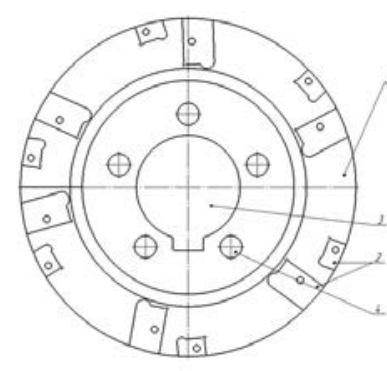

a)

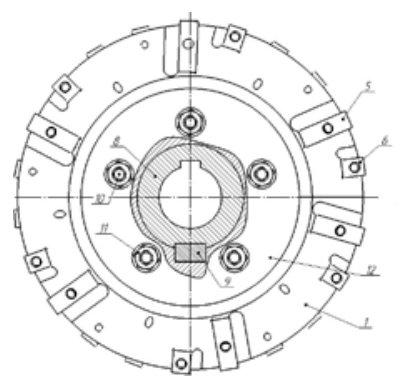

b)

Fig. 6. The assembly cutting hob with RCB

The tool is equipped with a plug and a feather key with a key seat in order to exclude a possibility of a crank of discs of the cutting hob case during milling cut. The discs are gathered on the plug and feather key and tied up by five pins which have screws on its ends. There are two disc jaws alone the edges of the case used for a best fastening of the assembly cutting hob discs.

The assembly cutting hob works in the following way: the tool is fastened on a gear milling machine, a milling cutter has a rotational mode on itself and translational mode along an axis of a part. The part fastened on a machine bench has only rotational mode on itself, strictly coordinated with the rotation of the assembly cutting hob.

Therefore the developed cutting hob is practical to fabricate because all basing surfaces for cutting carbide blades and key slots are designed so that abrasive disks used for grind finishing have a free access to them. Working capacity and reliability of the assembly cutting hob is increased In consequence of produceability of the tool case and usage of hard-alloy blades.

\section{References}

1. E. V. Artamonov, V. V. Kireev, V. A. Zyryanov, Improving the Efficiency of Hobbing Mills, Russian Engineering Research, v. 37(5), pp. 447-449 (2017)

2. E.V. Artamonov, T.E. Pomigalova, M.Kh. Uteshev, Calculation and designing of retrofittable indexible inserts and assembly tools (Tyumen, TyumGNGU, $2011-152 \mathrm{~s}$ )

3. E.V. Artamonov, T.E. Pomigalova, A.M. Tveryakov, M.Kh. Uteshev, Failure mechanics and durability of retrofittable indexible inserts made of hard alloys (Tyumen, TyumGNGU, 2013 - 148s)

4. E.V. Artamonov, I.A. Efimovich, N.I. Smolin, M.Kh. Uteshev, Stress strain condition and durability of tools cutting elements ( M.: Nedra, 2001. - $199 \mathrm{~s}$ )

5. E. V. Artamonov, V. V. Kireev, The Compound Hob For Processing Gearbox Pinions Used In Hoist For Well Repairs, Appl. Mech. Mater, v. 770, pp. 469-475 (2015)

6. Catalog, Ingersoll Werkzeuge GmbH, INGERSOLL Teeth, Haiger, (2008) 
7. E.V. Artamonov, Durability and working capacity of retrofittable hard alloy blades of assembly cutting tools (Tyumen, TyumGNGU, 2003. - $192 \mathrm{~s}$ )

8. E. V. Artamonov, V. V. Kireev, Effectiveness of cutting by hods with replaceable hard-alloy plates, J. Russ. Eng. Res, v. 37(7), pp. 473-474 (2014)

9. W. Liu, D. Ren, S. Usui, J. Wadell, T. D. Marusich, A gear cutting predictive model using the finite element method, J. CIRP, v. 8, pp. 51-56 (2013)

10. S. Steina, M. Lechthalera, S. Krassnitzera, K. Albrechta, A. Schindlerb, M. Arndta, $A$ contribution to analogy testing and its wear mechanisms, J. CIRP, v. 1(1) pp. 220-225 (2012)

11. T. Tokawa, Y. Nishimura, Y. Nakamura, High productivity dry hobbing system, J. Mitsubishi Heavy Ind, v. 38(1), pp. 27-31(2001) 